\title{
Current Trends Of Unethical Behavior Within Organizations
}

\author{
Octavia A. Askew, University of Phoenix, USA \\ Jeffrey M. Beisler, University of Phoenix, USA \\ Jetonga Keel, University of Phoenix, USA
}

\begin{abstract}
A substantial body of research reveals that unethical behavior continues to be a concern in the workplace. This article presents information on the prevalence of unethical behavior, antecedents of unethical behavior, the organizational environment, cognitive moral development, and trends of unethical behavior over a 3 year span. Findings of earlier studies generally agree that unethical behavior has a negative effect in the workplace. The greatest research effort on this issue has been to continue to conduct studies within organizations, identifying if the issue of unethical behavior is improving or stagnant.
\end{abstract}

Keywords: Ethics; Unethical Behaviors; Antecedents of Unethical Behavior; Behavioral Ethics

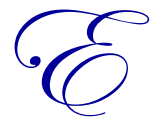

thical and unethical behaviors are behaviors that occur within organizations by employees on a daily basis (Jex \& Britt, 2008). Ethical behavior is the behavior companies seek to drive performance and success. Companies are highly concerned about unethical behavior for a number of reasons. Decreases in organizational performance, financial losses, reputational damage, safety concerns, and a loss of customers are all concerns that are connected with unethical behavior. Understanding the why behind these types of behaviors could possibly dictate the success of a given organization.

Therefore, within this paper, the areas of focus include understanding categories of antecedents and the most important category of antecedents with regard to unethical behavior in organizations. Abiding by standards and guidelines are imperative components to ensure that unethical behaviors do not occur within the workplace. Ethical actions within organizations is employee behavior that is just and above constitutional laws (Reiss \& Mitra, 1998). Companies want employees to exhibit ethical behavior in order to produce outcomes that are beneficial. In contrast, unethical behavior is an area of great concern. Unethical behavior violates generally accepted moral norms, is widespread, and the costs involved are high (Kaptein, 2011).

According to Gomez-Mejia and Balkin (2002), various countries follow different norms and internationally an important concern is defining ethical behavior. Business ethics serve as guidelines or standards for an organization when making decisions. When guidelines or standards are not present within the workplace, the organization is not on one accord in terms of the principles that are important and the criteria that determines unethical behavior (Gomez-Mejia \& Balkin, 2002). The purpose of this review is to explore current trends within organizations concerning unethical behavior. A discussion of ethical and unethical behavior within organizations is presented followed by an analysis of several studies relating to current trends within organizations.

\section{THE “WHY” BEHIND UNDERSTANDING ETHICAL BEHAVIOR}

According to McIntire and Miller (2007), ethics focuses on processes and topics that guide the decision making process in terms of what is right. Ethical standards are a group of professional process guidelines or codes for doing what is considered the right practice (McIntire \& Miller, 2007). Thus, ethics are important in order to ensure that processes and practices are doing what is considered to be morally right. Ethics differ from organization to organization based on the organization's specific ethical values and issues. According to Cascio and Aguinis (2011), employers have ethical responsibilities, which are often demonstrated through the execution of company 
ethics programs. Ethical actions are not dictated by specific and strict guidelines; it changes and evolves in response to social standards and the wishes and interests of those aided by the profession (Cascio \& Aguinis, 2011).

Business ethics are different from laws because in some circumstances it may not be illegal to engage in unethical behavior (Gomez-Mejia \& Balkin, 2002). According to Hoyk and Hersey (2009), an organization in which coworkers ignore, justify, or accept unethical behavior, is supporting the viewpoint of the transgressor. When moral standards are accepted by the majority of the group and a behavior or action by an employee exhibits behaviors or actions that do not reflect what is considered to be the norm, then the group would deem the behavior or action unethical (Kish-Gephart, Harrison, \& Trevino, 2010). Unethical behaviors that occur most frequently within the workplace setting are covering up problems, short-cutting quality of work, abusing sick days, and lying to customers (Gomez-Mejia \& Balkin, 2002).

Bowditch, Buono, and Stewart (2007) posit there are growing numbers of occurrences when employees experience situations where peers and supervisors encourage unethical behavior. For instance, unethical behavior may be an employee looking in the opposite direction of a wrongdoing, failure to report wrongdoings, or directly engaging in unethical activity (Bowditch et al., 2007). Cheney (2008) stated it is essential to understand how organizational cultures suppress or promote certain ethical practices (Bisel, Kelley, Ploeger, \& Messersmith, 2011). It is imperative to condemn unethical behavior and discourage the imitative practices, reducing the risk of an organizational culture that promotes political backstabbing that drives away talent and takes away the energy of the remaining employees (Gomez-Mejia \& Balkin, 2002).

When employees do not follow the written standards of the organization, the behavior impedes the organization's ability to meet corporate goals making understanding ethical behavior in organizations essential. Unethical behavior can impact the organization financially. For example, counterproductive behavior is a type of unethical behavior where actions go against the organization's goals (Jex \& Britt, 2008). Forms of counterproductive behavior include turnover, ineffective job performance, absenteeism, and unsafe behavior and additionally less common forms such as violence, theft, substance abuse, and sexual harassment (Jex \& Britt, 2008). These actions impact the organizations financial bottom-line and can cost the organization thousands of dollars each year (Jex \& Britt, 2008). Thus, it is critical to understand unethical behavior in organizations.

Unethical behaviors lead to detrimental consequences for others through ignoring rules, standards, regulations, and company guidelines (Tonus \& Oruç, 2012). The damaging consequences slow performance and growth. Unethical actions foster an environment of conflict, disrupt the company culture, and minimalize employee commitment, performance, and inspiration (Tonus \& Oruç, 2012). When employee commitment, performance, and motivation decrease the organization suffers significantly. As a result, companies want to prevent unethical behaviors and to promote ethical behaviors. The best option is through understanding the driving forces behind unethical decision-making in order to predict behavior.

\section{PREDICTING UNETHICAL BEHAVIOR: THE ANTECEDENTS}

According to Kish-Gephart, Harrison, and Trevino (2010), the three most important precursors of unethical behavior are the individuals, the ethical issue itself, and the organizational environment. The individual can be an antecedent to unethical behavior when considering the individual differences or characteristics of that person and how these differences influence unethical choices at work. Results presented from research conducted by KishGephart, Harrison, and Trevino (2010) state that individuals who make poor desions because of negative influences, think more for themselves than the group, exhibit counterproductive actions, avoid consequences for their actions, and fail to make the connection that their actions cause chain reactions will more than likely act in a manner that is unethical. Therefore, individuals who demonstrate behavior or actions that reflect negative characteristics are considered to be more prone to behavior that is unethical.

Additional antecedents of unethical behavior include moral identity, cognitive moral development, moral philosophies, and empathy (Moore, Detert, Trevino, Baker, \& Mayer, 2012). Moral identity refers to the indivdiuals reasonings skill, intuition, and perception, which represents their cognitive ability (Woo Jin \& Winterich, 2013). Virtuosity refers to moral traits, honesty, compassion, and fairness (Woo Jin \& Winterich, 2013). Cognitive moral 
development is the process of developing integrity, virtue, or character intentions (Andreoli \& Lefkowitz, 2009). Moral philosophies are basic beliefs about how to deal with ethical decision-making. Empathy is the ability to understand how others feel. Each antecedent offers insight into why people make unethical decisions.

Individual qualities, organizational characteristics, and cultural affects are categories of antecedents for predicting unethical behavior (Rusaw, 2001). Prominent qualities of an individual can be understood by the theories of moral development. Personal attributes to moral development occur as individuals mature in terms of education and experience, which provides the development for greater morality (Rusaw, 2001). Self-mastery is another component of moral development and as individuals mature they will develop self-control enabling the individual to self-reflect on actions and be able to adapt the actions to particular situations (Rusaw, 2001).

Rusaw (2001) posit organizational characteristics that hinder ethical development are organizational structure, organizational climate, job characteristics, and supervisory style. When the organization has a clear mission, ethical behavior within the organization may increase (Rusaw, 2001). According to Rusaw (2001), jobs that promote risk-taking to attain goals will foster behavior that is ethical if the risk taking is legitimate. Rusaw (2001) assert the cultural norms of an organization can inhibit consequently a member's ethical development. Organizations must realize the factors that influence ethical growth including the level of responsibility, potential to take risks, decision making authority, and the amount of accountability (Rusaw, 2001). Cultural affects consist of belief systems, which develop from family, religion, values, and school socialization (Rusaw, 2001). Rusaw (2001) stated, when the atmosphere consists of trust, fairness, and personal security, individuals will learn how to appropriately make and enforce rules.

\section{ORGANIZATIONAL ENVIRONMENT NAMED MOST IMPORTANT ANTECEDENT}

Of the three categories of antecedents to unethical behavior, it is argued the most important category in understanding unethical behavior is the organizational environment. The individual and the ethical issue itself are antecedents of unethical behavior, but can be considered factors that cannot be changed. However, the organization environment can be changed in order to influence the behavior of employees. The organizational environment includes the ethical climate, culture, and codes of conduct established within the organization. Ethical climate is based on what the majority group considers to be ethically sound and what the group has collectively identified to be issues that are deemed unethical in which the group is to resolve. The shared viewpoints of ethical appropriateness and the approach to addressing ethical issues in the company is the ethical climate (Peterson, 2002).

According to Bowditch, Buono, and Stewart (2007), organizational climate is about measuring the extent to which individual's expectations of working within an organization are met. Organizational climate is a perception of measurement and includes job performance, satisfaction of the job, interaction within groups, and withdrawal behaviors (Bowditch, Buono, \& Stewart, 2007). The commonality of beliefs which are shared and actions which reflect the common beliefs demonstrates an ethically sound culture (Key, 1999). Corporate codes of conduct use instruments to re-direct an employee's action and set in place characteristics that exhibit responsibility within the organization (Erwin, 2011).

According to Winthanage (2010), a code of ethics or conduct is a statement of central company values supporting best practices, behaviors, and standards and although each code of ethics may vary from company to company, there are several ethics that are held in common. Trust, honesty, fairness, respect, and equality are common ethics and adhering to these qualities is considered to be ethical behavior while straying from these qualities would be considered unethical behavior (Winthanage, 2010). It is not enough to have a code of ethics, but rather enforce the policies established. According to Winthanage (2010), standards and guidelines are to be established to prevent an environment that promotes a workplace that is unethical. Establishing and enforcing the code of conduct or ethics will help in creating an organizational environment that encourages ethical behavior amongst employees.

Research from Key (1999) suggests that the individual employee may be influenced by certain behaviors in the workplace changing their perception of ethical behavior. Additionally, the way in which an employee is treated will dictate their actions and behaviors (Key, 1999). Thus, how an employee views the culture of an organization 
will influence their decision when faced with an ethical dilemma. For example, culture upholds standards and enforces the following of the rules fostering ethical behavior from employees. In addition, research indicates when an organization has high morals and is ethically sound, the employee conducts their behavior in a suitable responsible manner (Erwin, 2011). Thus, implementing high quality codes of conducts will assist in promoting an organizational culture that is ethical.

According to Peterson (2002), research has proposed that a connection exists between the ethical environment and actions of workers. The results from a study by Peterson (2002) replicates the findings of Trevino et al. (1998) which indicates that even if ethical climate is established within the workplace, a lack of code of conduct or ethics can still create a workplace where observed unethical behaviors still occur. In addition, the study also demonstrated that having standards and guidelines regarding ethics promotes different behaviors than an organization that does not have a set of ethical guidelines. A final finding from the study was that ethical climates can be improved in an effort to improve the behavior of employees (Peterson, 2002). The organizational environment can be analyzed in various ways in order to understand why it is an antecedent to unethical behavior. Because of the various levels of analysis, the organizational environment is the most important category of antecedents to unethical behavior.

\section{COGNITIVE MORAL DEVELOPMENT}

Cognitive moral development is said to be a common determinant of one's behavior, which is linked to ethicality (Andreoli \& Lefkowitz, 2009). As such, moral development requires close examination in order to predict unethical decisions. As mentioned earlier, moral development is conceptualized by integrity, virtue, or character (Andreoli \& Lefkowitz, 2009). A person's character or level of integrity offers a means of understanding thoughts about how the person perceives unethical decisions. The importance of moral development is evident by the use of personnel selection tests that focus on integrity scores (Andreoli \& Lefkowitz, 2009). Research shows that integrity test scores are valid when reviewing job performance (Andreoli \& Lefkowitz, 2009). Also, there are significant relationships between individuals' scores on measures of moral judgment and behavioral conclusions such as delinquency, honesty, and altruism (Andreoli \& Lefkowitz, 2009). The connection highlights the importance of moral development as it relates to understanding unethical behavior.

Employee intentions to make unethical decisions are necessary considerations. Moral development relates to outcomes such as ethical intentions (Andreoli \& Lefkowitz, 2009). An awareness of moral development offers knowledge about ethical intentions. When ethical intentions are known, predicting unethical behaviors follow. For example, if it is known that an employee intends to cheat to gain success, the company may take actions to prevent unethical behaviors. Further, knowing ethical intentions prior to offering employment allows companies to make appropriate hiring decisions.

As discussed, moral development focuses on integrity, virtue, or character. Moral development occurs through a development of moral self, character, identity, reasoning, sensitivity, and consceicnce along with superego (Sherblom, 2012). Each component is associated with integrity, virtue, or character. An understanding of each component, offers a clear indication of behavior intentions. For example, a person with a strong conscience about unethical behavior may be less likely to behave unethically. That is why understanding moral development is of extreme importance in terms of understanding unethical behavior. Moral development is the category of antecedents that is needed to make accurate unethical behavior predictions.

\section{UNETHICAL BEHAVIOR TRENDS}

Unethical behavior is a concern for organizations. Inappropriate use of company time and resources, abusive treatment, and violations of internet policies are common unethical behaviors others report observing (Verschoor, 2012). Other interesting trends relate to culture and whistle blowing. The perception of poor ethical cultures at companies is increasing (Verschoor, 2012). There is a seemly acceptable environment of acting in an unethical manner. Unfortunately, employees reporting claims of retaliation after reporting unethical behavior is rising (Verschoor, 2012). The trends highlight critical concerns for companies. An increasing unethical business culture and increasing retaliation claims for reporting such behavior create the optimal environment for unethical 
behavior to occur. The unethical environment is risky for organizations. The trends demonstrate the need to better understand the root causes of unethical behavior.

According to Moore, Detert, Trevino, Baker, and Mayer (2012), research on moral disengagement has provided an inadequate understanding for the reason behind predictions of unethical behavior. In a web-based survey conducted by a university in the U.S, undergraduate business students participate in a span of four surveys to demonstrate how propensity of moral disengagement can be used to predict different types of unethical behavior within organizations (Moore et al., 2012). Moore et al., (2012) said moral disengagement is relative to individual differences based upon three constructs. These constructs focus on morality when considering the individual's personality traits, reasoning skills, and emotional disposition. The findings concluded that both practitioners and scholars should consider an individual's propensity in order to understand workplace behaviors that are undesirable (Moore et al., 2012).

In 2013, workforce organizations such as Walmart, Lockheed Martin Corporation, Altria Group, Inc., Edison International, United Technologies Corporation, PricewaterhouseCoopers LLP, Corporation Raytheon, KPMG LLP, SAIC, Assurant, Inc., BAE Systems, Archer Daniels Midland, and Bechtel Group, Inc. participated in the (NBE) National Business Ethics Survey. The findings concluded that there has been a decline in observed misconduct in addition to the influential factors with regard to compromising standards (ERC, 2014). Findings also reported that reporting and retaliation within the workforce has not improved and one-third of participants do not report because of fear of retaliation from senior leaders (ERC, 2014). Participants who experienced retaliation in the past had a lower willingness to report when compared to participants who never experienced retaliation (ERC, 2014).

A study conducted by Zuber and Kaptein (2014) empirically explored the relationship of the observer and self-reporter among a Swiss population of workers. There were 37 different types of unethical behaviors under investigation and the findings suggested that the ration of self-report and observed report varied in the type of unethical behavior. The results concluded that researchers should not assume that the frequency of self-reporting should be approximated by the observer-reporter frequency (Zuber \& Kaptein, 2014).

Welsh and Ordóñez (2014) contend that specific, challenging, and unachievable performance goals may motivate unethical behavior within an organization. Goals with cash value and goals with no external rewards were found to motivate unethical behavior (Welsh \& Ordóñez, 2014). Goal-based compensation systems increased unethical behavior more than linear piece-rate and tournament-based compensation (Welsh \& Ordóñez, 2014). Performance goals can increase unethical behavior due to creating high cognitive loads that focus mental processes on goal attainment as oppose to moral standard (Welsh \& Ordóñez, 2014).

According to Aleassa and Megdadi (2014), workplace bullying can influence unethical behaviors within the workplace. The research conducted was an attempt to fill the void of describing the connection between workplace bullying and unethical actions (Aleassa \& Megdadi, 2014). The authors created a mediation model to examine bullying and how employees react, which explains why and how workplace bullying encourages unethical behavior among employees (Aleassa \& Megdadi, 2014). Based on the model proposed, a primary and secondary effect of workplace bullying occurs on employees' decision to commit unethical behaviors (Aleassa \& Megdadi, 2014). Results of the study indicated that workplace bullying positively connected with rating of unethical actions, negatively with psychological ownership, and bullying described significant discrepancy in self-reported unethical behavior (Aleassa \& Megdadi, 2014).

\section{CONCLUSION}

In conclusion, the review provided an overview of the importance of understanding ethical behavior in companies. Specifically, the researchers described the different categories of antecedents in forecasting unethical behavior, the three antecedent categories, and the most important antecedent in understanding unethical behavior. Current trends in unethical behavior was also provided. Understanding ethical behavior within organizations is important as employees who engage in unethical behavior impede the organization's ability to achieve goals. There are three categories of antecedents of unethical behavior including the individual, the ethical issue itself, and the 
organizational environment. Of these three categories, it is argued that the organizational environment is the most important in understanding unethical behavior as the organizational environment can influence the employee's behavior on various levels. Analyzing the importance of ethical behavior in organizations and the precursors to unethical behavior will assist in providing a more complete picture of understanding ethical and unethical actions in companies. Therefore, each component within the article provides resourceful information that can be applicable to various organizations and further the development of growth of ethical behavior.

\section{AUTHOR INFORMATION}

Jeffrey M. Beisler, CTP, PHR, SHRM-CP, MS-IOP, is an industrial/organizational psychology Ph.D. student at University of Phoenix and a senior vice president at Wells Fargo \& Company. He holds a M.S. in industrial/organizational psychology, a B.S. in Business Finance, and an A.A. in financial services all from University of Phoenix. He is a Certified Treasury Professional, a Professional in Human Resources, and a Society for Human Resource Management Certified Professional. Email: Jeffrey.Beisler@gmail.com (Contact author)

Octavia Askew, MHA/MS-IOP, is currently a Ph.D student in the field of industrial/organizational psychology at University of Phoenix. She is a wellness and education director contracting at various locations in the Los Angeles county. She received her M.S in health administration and M.S in industrial/organizational psychology from the University of Phoenix. She received her B.S. Degree from Cal State University of Dominguez Hills in Biology while being a member of The Minority Access to Research Careers-Undergraduate Student Training in Academic Research (MARC-U*STAR) Program and Minority Biomedical Research Support-Research Initiative for Scientific Enhancement (MBRS-RISE) Program. Email: oaskew2000@yahoo.com

Jetonga Keel, MBA/MHA, MS-IOP, CPC is an industrial/organizational psychology Ph.D. doctoral candidate at University of Phoenix and professor of health care and business administration and psychology courses with several universities and colleges across the U.S. She holds a M.S. in industrial/organizational psychology, dual Master's degree in business and health administration from Pfeiffer University, and B.A. in psychology and Afro-American studies from UNC-Chapel Hill. She also has her CPC (certified professional coder) certification from the American Academy of Professional Coders (AAPC). E-mail: jetonga24@yahoo.com

\section{REFERENCES}

Aleassa, H. M., \& Megdadi, O. D. (2014). Workplace bullying and unethical behaviors: A mediating model. International Journal of Business and Management, 9(3), 157-169. doi:10.5539/ijbm.v9n3p157

Andreoli, N., \& Lefkowitz, J. (2009). Individual and organizational antecedents of misconduct in organizations. Journal of Business Ethics, 85(3), 309-332. doi:10.1007/s10551-008-9772-6

Bisel, R. S., Kelley, K. M., Ploeger, N. A., \& Messsersmith, J. (2011). Workers'moral mum effect: On facework and unethical behavior in the workplace. Communication Studies, 62(2), 153-170. doi: $10.1080 / 10510974.2010 .551314$

Bowditch, J.L., Buono, A.F., \& Stewart, M.M. (2007). A primer on organizational behavior (7th ed.). Hoboken, NJ: John Wiley \& Sons.

Cascio, W.F., \& Aguinis, H. (2011). Applied psychology in human resource management. Upper Saddle River, NJ: Prentice Hall.

Cheney, G. (2008). Encountering the ethics of engaged scholarship. Journal of Applied Communication Research, 36, 281-288. doi: 10.1080/00909880802172293

Erwin, P. (2011). Corporate codes of conduct: The effects of code content and quality on ethical performance. Journal of Business Ethics, 99(4), 535. doi:10.1007/s10551-010-0667-y

Ethics Resource Center. (2014). National Business Ethics Survey. Retrieved from http://www.ethics.org/nbes/download-reports/2013nbes/

Gomez-Mejia, L.R., \& Balkin, D.B. (2002). Management. USA: McGraw-Hill.

Hoyk, R., \& Hersey, P. (2009). The root causes of unethical behavior. Graziadio Business Report, 12(2), 1-5.

Jex, S. \& Britt, T. W. (2008). Organizational psychology: A scientist-practitioner approach (2nd ed.). Hoboken, NJ: Wiley. 
Kaptein, M. (2011). Toward effective codes: Testing the relationship with unethical behavior. Journal of Business Ethics, 99(2), 233-251. doi:10.1007/s10551-010-0652-5

Key, S. (1999). Organizational ethical culture: real or imagined? Journal of Business Ethics, 20(3), 217.

Kish-Gephart, J. J., Harrison, D. A., \& Trevino, L. K. (2010). Bad apples, bad cases, and bad barrels: Meta-analytic evidence about sources of unethical decisions at work. Journal of Applied Psychology, 95(1), 1. doi: $10.1037 / \mathrm{a} 0017103$

McIntire, S. A., \& Miller, L. A. (2007). Foundations of psychological testing: A practical approach (2nd ed.). Thousand Oaks, CA: Sage.

Moore, C., Detert, J. R., Trevino, L., Baker, V. L., \& Mayer, D.M. (2012). Why employees do bad things: Moral disengagement and unethical organizational behavior. Personnel Psychology, 65(1), 1-48. doi:10.1111/j.1744-6570.2011.01237.x

Peterson, D. K. (2002). The relationship between unethical behavior and the dimensions of the ethical climate questionnaire. Journal of Business Ethics, 41(4), 313-326.

Reiss, M. C., \& Mitra, K. (1998). The effects of individual difference factors on the acceptability of ethical and unethical workplace behaviors. Journal of Business Ethics, 17(14), 1581-1593. Retrieved from http://www.springer.com/social+sciences/applied+ethics/journal/10551

Rusaw, A.C. (2001). Leading public organizations an interactive approach. New York, NY: Harcourt College Publishers.

Sherblom, S. A. (2012). What develops in moral development? A model of moral sensibility. Journal of Moral Education, 41(1), 117-142. Retrieved from http://www.tandfonline.com/toc/cjme20/current\#.UiNuzGS4G18

Tonus, H., \& Oruç, İ. (2012). Unethical behaviors and their management in human resource management: A content analysis of a company's personnel regulation. Turkish Journal of Business Ethics, 5(10), 173-181. Retrieved from http://www.isahlakidergisi.com/en/?act=detay\&ID=35

Welsh, D. T., \& Ordóñez, L. D. (2014). The dark side of consecutive high performance goals: Linking goal-setting, depletion, and unethical behavior. Organizational Behavior and Human Decision Processes, 123(2), 79-89. doi:10.1016/j.obhdp.2013.07.006

Withanage, A. J. (2010). Motivated to be unethical. International Journal of Interdisciplinary Social Sciences, 5(3), 55-69.

Woo Jin, C., \& Winterich, K. (2013). Can brands move in from the outside? How moral identity enhances out-group brand attitudes. Journal of Marketing, 77(2), 96-111. Retrieved from http://www.marketingpower.com

Verschoor, C. C. (2012). New survey of workplace ethics shows surprising results. Strategic Finance, 93(10), 13-15.

Zuber, F. F., \& Kaptein, M. M. (2014). Painting with the same brush? Surveying unethical behavior in the workplace lusing self-reports and observer-reports. Journal of Business Ethics, 125(3), 401-432. doi:10.1007/s10551-013-1920-y 


\section{NOTES}

